\title{
Helicobacter pylori Inhibits Dendritic Cell Maturation via Interleukin-10-Mediated Activation of the Signal Transducer and Activator of Transcription 3 Pathway
}

\author{
David Rizzutia, ${ }^{a}$ Michelle Ang ${ }^{a, b} \quad$ Christiane Sokollik ${ }^{a, b}$ Ted Wu ${ }^{a, b}$ \\ Majd Abdullaha, b Laura Greenfield ${ }^{a, b} \quad$ Ramzi Fattouh $^{b} \quad$ Colin Reardon $^{d}$ \\ Michael Tang ${ }^{c}$ Jun Diao ${ }^{c}$ Christian Schindler ${ }^{\mathrm{e}}$ Mark Cattral $^{c}$ Nicola L. Jones $^{\mathrm{a}, \mathrm{b}}$ \\ aDepartments of Paediatrics and Physiology, University of Toronto, ${ }^{b}$ Cell Biology Program, Hospital for Sick Children \\ and ${ }^{\mathrm{C} T o r o n t o}$ General Hospital Research Institute, University Health Network, Toronto, Ont., Canada; ${ }^{\mathrm{d}}$ Developmental \\ Immunology-2, La Jolla Institute for Allergy and Immunology, La Jolla, Calif., and ' Department of Medicine, \\ Columbia University, New York, N.Y., USA
}

\section{Key Words}

Immune response - Bacteriology · Cytokines · H. pylori .

Dendritic cells

\begin{abstract}
Helicobacter pylori infects the human gastric mucosa causing a chronic infection that is the primary risk factor for gastric cancer development. Recent studies demonstrate that H. pylori promotes tolerogenic dendritic cell (DC) development indicating that this bacterium evades the host immune response. However, the signaling pathways involved in modulating DC activation during infection remain unclear. Here, we report that $H$. pylori infection activated the signal transducer and activator of transcription 3 (STAT3) pathway in murine bone marrow-derived DCs (BMDCs) and splenic DCs isolated ex vivo. Isogenic cagA-, cagE-, vacA- and urease-mutants exhibited levels of phosphoSTAT3 that were comparable to in the wild-type (WT) parent strain. H. pylori-infected BMDCs produced increased immunosuppressive IL-10, which activated STAT3 in an autocrine/paracrine fashion. Neutralization of IL-10 prevented $\mathrm{H}$. pylori-mediated STAT3 activation in both BMDCs and splenic DCs. In addition, antiIL-10 treatment of infected H. pylori-BMDCs was associated
\end{abstract}

with increased CD86 and MHC II expression and enhanced proinflammatory IL-1 $\beta$ cytokine secretion. Finally, increased CD86 and MHC II expression was detected in H. pylori-infected STAT3 knockout DCs when compared to WT controls. Together, these results demonstrate that $H$. pylori infection induces IL-10 secretion in DCs, which activates STAT3, thereby modulating $D C$ maturation and reducing IL- $1 \beta$ secretion. These findings identify a host molecular mechanism by which $H$. pylori can manipulate the innate immune response to potentially favor chronic infection and promote carcinogenesis.

두 2014 S. Karger AG, Basel

\section{Introduction}

Helicobacter pylori infects almost 50\% of the worldwide human population and is a significant risk factor for the development of gastric cancer $[1,2]$. H. pylori infection induces an inflammatory response in the gastric mucosa consisting of infiltrating lymphocytes, neutrophils and dendritic cells (DCs) that is insufficient to eradicate infection, indicating that the bacterium has developed mechanisms to subvert the host immune response. DCs

\section{KARGER 125}

(c) 2014 S. Karger AG, Basel

1662-811X/14/0072-0199\$39.50/0

E-Mail karger@karger.com

www.karger.com/jin
Dr. Nicola L. Jones

Division of Gastroenterology, Hepatology and Nutrition

Hospital for Sick Children, 555 University Ave

M5G 1X8 Toronto, ON (Canada)

E-Mail nicola.jones@sickkids.ca 
are key modulators of the host adaptive immune response [3]. Upon encounters with antigens, immature DCs take up, process and present antigenic fragments on surface MHC II molecules and display elevated levels of the maturation markers CD80/86 and MHC II. Mature DCs secrete specific cytokines to drive the differentiation of the $\mathrm{T}$ cell into distinct helper $\mathrm{T}$ (Th) cell subsets, including Th1, Th2 and Th17, each of which responds to specific pathogens or antigens. In addition, DCs can drive the development of regulatory $\mathrm{T}$ cells (Tregs) to prevent immune reactivity to autoantigens and commensal bacteria, thereby promoting immunologic tolerance. Tolerogenic DCs can promote immune tolerance by deleting autoreactive $\mathrm{T}$ cells, priming anergic $\mathrm{T}$ cells or promoting Treg development [3]. Treg-inducing DCs express reduced levels of maturation molecules such as MHC II, CD80 and CD86, and secrete high levels of the immunosuppressive cytokine IL-10 compared to classically activated DCs [3]. Importantly, the presence of IL-10 during maturation drives the production of tolerogenic DCs, creating a positive feedback loop to induce maturation of more tolerogenic DCs.

Several recent studies indicate that $H$. pylori infection promotes the development of tolerogenic DCs, both in vitro in a coculture system and in vivo in murine models $[4,5]$. H. pylori infection of neonatal mice induces the development of DCs that preferentially induce Tregs in coculture. DC depletion prior to infection in neonatal mice promotes more severe gastritis and reduces bacterial colonization, providing support for the role of these tolerogenic DCs in modulating infection. In another study, the adoptive transfer of $H$. pylori-stimulated DCs into mice prior to orogastric infection promoted the development of increased $H$. pylori-specific Tregs [4]. In murine models of inflammatory disease, the reprogramming of DCs by $H$. pylori infection or exposure to $H$. pylori DNA is protective against allergic asthma and colitis, respectively $[5,6]$. In addition, impaired DC function may contribute to carcinogenesis during chronic infection. Taken together, these studies indicate that $H$. pylori promotes the development of tolerogenic DCs. However, the exact host cell signaling mechanisms by which $H$. pylori modulates DC activity remain unclear.

Signal transducer and activator of transcription (STAT) 3 is a member of the STAT family of signal transducer proteins that are activated by tyrosine phosphorylation cascades in response to ligand binding. STAT3 is activated in response to cytokines and growth factors such as IL-6, IL-10 and vascular endothelial growth factor [7]. Ligand binding to its cognate cell surface receptor promotes dimerization with the gp130 subunit, resulting in the phosphorylation and activation of associated Janus kinase (JAK) 2 enzymes that subsequently recruit cytoplasmic STAT3 to the gp130 subunit [8]. STAT3 becomes phosphorylated on Y705, and dimerizes through Src-homology 2 domain ( $\mathrm{SH} 2)$ phosphotyrosine interactions. Phosphorylated STAT3 then translocates into the nucleus [9], where it binds to promoter regions of target genes involved in cell maturation, growth, proliferation, angiogenesis and immune function $[8,10,11]$.

In DCs, STAT3 activation inhibits DC activation and chemical or genetic inhibition of STAT3 activity promotes DC maturation $[7,12]$. IL-10 signals via the STAT3 pathway, and the presence of this cytokine during DC maturation produces tolerogenic DCs [3]. In this study, we determined whether $H$. pylori activates STAT3 in DCs as a potential means of subverting the host immune response to promote chronic infection.

\section{Materials and Methods}

Bone Marrow-Derived DCs

Bone marrow-derived DCs (BMDCs) were obtained and cultured from C57BL6 wild-type (WT) mice that were 6-8 weeks of age. DCs were also obtained from STAT3 CD11c-Cre knockout (KO) mice or littermate controls [12]. Animal treatment and care was carried out according to the guidelines outlined by the SickKids Lab Animal Services. Bone marrow was extracted from the femur and tibia and seeded at $2 \times 10^{5}$ cells $/ \mathrm{ml}$ with DC media [13]. DC media contains: RPMI-1640 media, 10\% fetal bovine serum, $1 \%$ L-glutamine, $1 \%$ penicillin/streptomycin, $1 \mathrm{X}$ sodium pyruvate, $1 \mathrm{X}$ nonessential amino acids and $0.1 \%$ 2-mercaptoethanol. Recombinant murine GM-CSF was added at a concentration of 40 $\mathrm{ng} / \mathrm{ml}$ for stimulating DC growth [13]. DCs were seeded on bacteriological Petri dishes with $10 \mathrm{ml} \mathrm{DC}$ media supplemented with GM-CSF for 3 days at $37^{\circ} \mathrm{C}$ in $5 \% \mathrm{CO}_{2}$. On day 3, an additional 10 $\mathrm{ml}$ of DC media supplemented with GM-CSF was added to each plate. On day 6 and day $8,10 \mathrm{ml}$ of the solution from each plate was removed, centrifuged to pellet floating cells, and resuspended with $10 \mathrm{ml}$ of fresh DC media supplemented with GM-CSF per plate. On day 10, the floating, nonadherent cell population (i.e. immature DCs) was harvested, counted and plated in 6-well tissue culture plates in antibiotic-free DC media to be used for treatment/ infection.

\section{Isolation of Splenic DCs for in vitro Culture}

Splenic DCs were obtained from the spleens of B16-Flt3L-treated C57BL/ 6 mice. Briefly, the mice were inoculated with $0.5-1 \times 10^{6}$ B16 melanoma cells overexpressing Flt3L for 12-14 days. Spleens were isolated, minced and digested with collagenase and DNase-I for $0.5 \mathrm{~h}$ at $37^{\circ} \mathrm{C}$, and incubated in PBS containing $2 \mathrm{mM}$ EDTA and $5 \%$ FCS for $10 \mathrm{~min}$ at room temperature. Mononuclear cells were isolated by Nycodenz density gradient centrifugation. Negative selection for lineage markers and Gr-1 was performed using biotinconjugated antibodies (Becton Dickson, San Jose, Calif., USA) and 
streptavidin-immunomagenetic beads (Miltenyi). Cells were further enriched for CD $11 \mathrm{c}^{+}$cells by positive selection using CD11 $\mathrm{c}^{+}-$ immunomagnetic beads (Miltenyi). The purity of the cell population used was routinely $95 \%$ based on reanalyzed samples.

\section{Treatment/Infection of DCs}

H. pylori strain 60190 (ATCC $43526 \mathrm{cagA}+, \mathrm{cag} E+, \mathrm{vacA}$ $s 1 m 1+$ ) and its isogenic cagA-, cagE-, vacA- and urease-mutants and the gerbil-adapted carcinogenic strain $7.13(c a g A+, c a g E+$ and $v a c A-)$ and its corresponding isogenic cagA-mutant were cultured as described previously on Columbia blood agar plates (supplemented with $5 \%$ sheep blood) under microaerophilic conditions $\left(5 \% \mathrm{O}_{2}, 10 \% \mathrm{CO}_{2}\right.$ and $\left.85 \% \mathrm{~N}_{2}\right)$ for $72 \mathrm{~h}[14,15]$. Bacteria were collected using sterile inoculation loops and transferred into a bacterial flask containing Brucella broth supplemented with $10 \%$ fetal bovine serum for $24 \mathrm{~h}$. Bacteria were then harvested by centrifugation, resuspended in DC media and added to immature DCs at a multiplicity of infection (MOI) of 25:1, 10:1, 5:1, or 1:1. Treated cells were incubated at $37^{\circ} \mathrm{C}$ for $20 \mathrm{~h}$. Untreated DCs served as control cells. DCs treated with IL-6 $(100 \mathrm{ng} / \mathrm{ml})$ served as a positive control for STAT3 activation [16]. The concentration of IL-6 employed was based on previous studies assessing STAT3 activation in epithelial cells [15]. Groups of DCs were treated with low-dose Escherichia coli lipopolysaccharide (LPS; Sigma Aldrich) at a minimal concentration $(1 \mathrm{ng} / \mathrm{ml})$ determined to induce DC maturation [17]. In some experiments, DCs were treated with a neutralizing rat-anti-mouse IL-10 antibody $(0.5 \mu \mathrm{g} / \mathrm{ml}$ or $1 \mu \mathrm{g} / \mathrm{ml}$; eBioscience, San Diego, Calif., USA) or a rat-anti-IgG antibody ( $1 \mu \mathrm{g} /$ $\mathrm{ml}$; BioLegend, San Diego, Calif., USA). After 20 h of incubation, the cells were harvested for analysis.

\section{Western Blotting}

After $20 \mathrm{~h}$ of treatment/infection, cells were harvested by vigorous pipetting and washed with phosphate-buffered saline (PBS; Sigma Aldrich). Cells were lysed using $100 \mu \mathrm{l}$ of a radioimmunoprecipitation assay buffer cocktail supplemented with protease inhibitors on ice. Lysates were centrifuged, and supernatants were collected and stored at $-20^{\circ} \mathrm{C}$ [15]. Lysates (supplemented with $10 \%$ Laemelli buffer) were loaded onto $12 \%$ SDS-polyacrylamide gels and run at $110 \mathrm{~V}$ at room temperature for $1.5 \mathrm{~h}$. Separated proteins were transferred onto nitrocellulose membrane (BioTrance, NT; Pall Corp., Ann Arbor, Mich., USA) at $30 \mathrm{~V}$ for $8 \mathrm{~h}$ at $4{ }^{\circ} \mathrm{C}$ [15]. Membranes were then blocked with $5 \%$ skim milk made using Tris-buffered saline supplemented with tween (TBST) for $30 \mathrm{~min}$, followed by overnight incubation at $4^{\circ} \mathrm{C}$ using rabbit-anti-phosphorylated STAT3 (PSTAT3) antibody (1:200; Cell Signaling, Mass., USA) and mouse-anti-actin antibody $(1: 10,000)$ in TBST milk. Blots were then incubated using corresponding horseradish peroxidase-conjugated secondary antibodies (1:2,000 and 1:10,000 for the PSTAT3 and actin primary antibodies, respectively) for $1 \mathrm{~h}$ at room temperature [15]. Bands were then visualized by chemiluminescence using Kodak Biomax MR film or FluorChem E Imager (Proteinsimple, Santa Clara, Calif., USA).

\section{Densitometric Analysis}

Densitometry was performed utilizing the FlourChem FCII software. Densities of PSTAT3 and actin bands were measured for each treatment and expressed as a ratio of PSTAT3/actin, normalized to the control treatment.

\footnotetext{
H. pylori Activates STAT3 in Dendritic
} Cells

\section{Flow Cytometry}

After $20 \mathrm{~h}$ of treatment/infection, DCs were harvested by vigorous pipetting and centrifuged at $350 \mathrm{~g}$ for $10 \mathrm{~min}$. Supernatants were collected and stored at $-80^{\circ} \mathrm{C}$ to examine cytokine release profile. Cells were rinsed using flow cytometry buffer (PBS supplemented with $1 \% \mathrm{BSA}$ ), and then incubated with $25 \mu \mathrm{g} / \mu \mathrm{l}$ antiCD16/32 (FC receptor block; eBioscience) for 15 min on ice, to block nonspecific antibody binding [18]. BMDCs were then incubated with FITC-labeled aCD11c, PE-labeled aCD86 and APC-labeled aMHC class II antibodies (all from eBioscience) for $30 \mathrm{~min}$. Isolated splenic DCs were incubated with FITC-labeled aCD11c, PE-labeled aCD86 and PE-Cy7-labeled aMHC class II antibodies and subsequently incubated with $7-\mathrm{AAD}$ viability staining solution (eBioscience). DCs were then washed twice with FBS before fixation using $1 \%$ paraformaldehyde (made with PBS) for $20 \mathrm{~min}$. Cells were subsequently washed with flow cytometry buffer and analyzed using a LSR-II flow cytometer (Becton Dickson). Flow cytometry data was then analyzed utilizing FlowJo software (Tree Star Inc., Ashland, Oreg., USA). Live BMDCS were selected based on the size, complexity and expression of the DC-specific marker CD11c. Populations were analyzed based on the proportion of cells positive for the maturation markers MHC II and CD86 (mature DCs). Live isolated splenic DCs were selected based on exclusion of the 7-AAD viability staining solution, size and complexity, and the expression of the DC-specific marker CD11c.

\section{Multiplex Bead-Based Luminex Assay}

DCs were infected for $20 \mathrm{~h}$ as described above. Supernatants were collected and stored at $-80^{\circ} \mathrm{C}$. Supernatants from DCs were assayed for the CD40 ligand, GM-CSF, IFN- $\gamma$, IL-10, IL-12 (p70), IL-13, IL-15, IL-17A, IL-17E/IL-25, IL-17F, IL-1 $\beta$, IL-2, IL-21, IL22, IL-23, IL-27, IL-28B, IL-31, IL-33, IL-4, IL-5, IL-6, MIP-3a/ CCL20, TNF $\alpha$ and TNF $\beta$, using the mouse Th17 magnetic bead kit (EMD Millipore, Billerica, Mass., USA). The service was performed by the Centre for the Study of Complex Childhood Diseases at the Hospital for Sick Children, Toronto, Ont., Canada.

\section{ELISA Assay}

Isolated splenic DCs were infected for $20 \mathrm{~h}$ as described above. Supernatants were collected and stored at $-80^{\circ} \mathrm{C}$. Supernatants from DCs were assayed for IL- $1 \beta$ and IL-10 using the mouse quantikine IL-1 $\beta$ and IL-10 kits, respectively (R\&D Systems).

\section{STAT3 KO Mice}

STAT3 KO mice were kindly donated by the laboratories of Dr. Tak Mak and Dr. Christian Schindler. These DC-specific STAT3 $\mathrm{KO}$ mice were generated using a Cre-flox system as described previously [12]. Briefly, STAT3 ${ }^{\text {flox/flox }}$ mice in a $129 / \mathrm{C} 57 \mathrm{BL} / 6 \mathrm{~J}$ mixed background were crossed seven generations onto C57BL/6J background, and then with CD11c-BAC-Cre transgenic mice. STAT3 expression was assessed in cell lysates via immunoblotting to confirm knockout.

\section{Statistical Analysis}

All experiments were performed at least 3 times, and statistical significance was calculated using the Kruskal-Wallis nonparametric 1-way analysis of variance (ANOVA) testing to compare the means \pm SE for independent treatment groups followed by Dunn's testing or a 1-way ANOVA to compare the means \pm SE where noted. A p value $<0.05$ was considered statistically significant. 


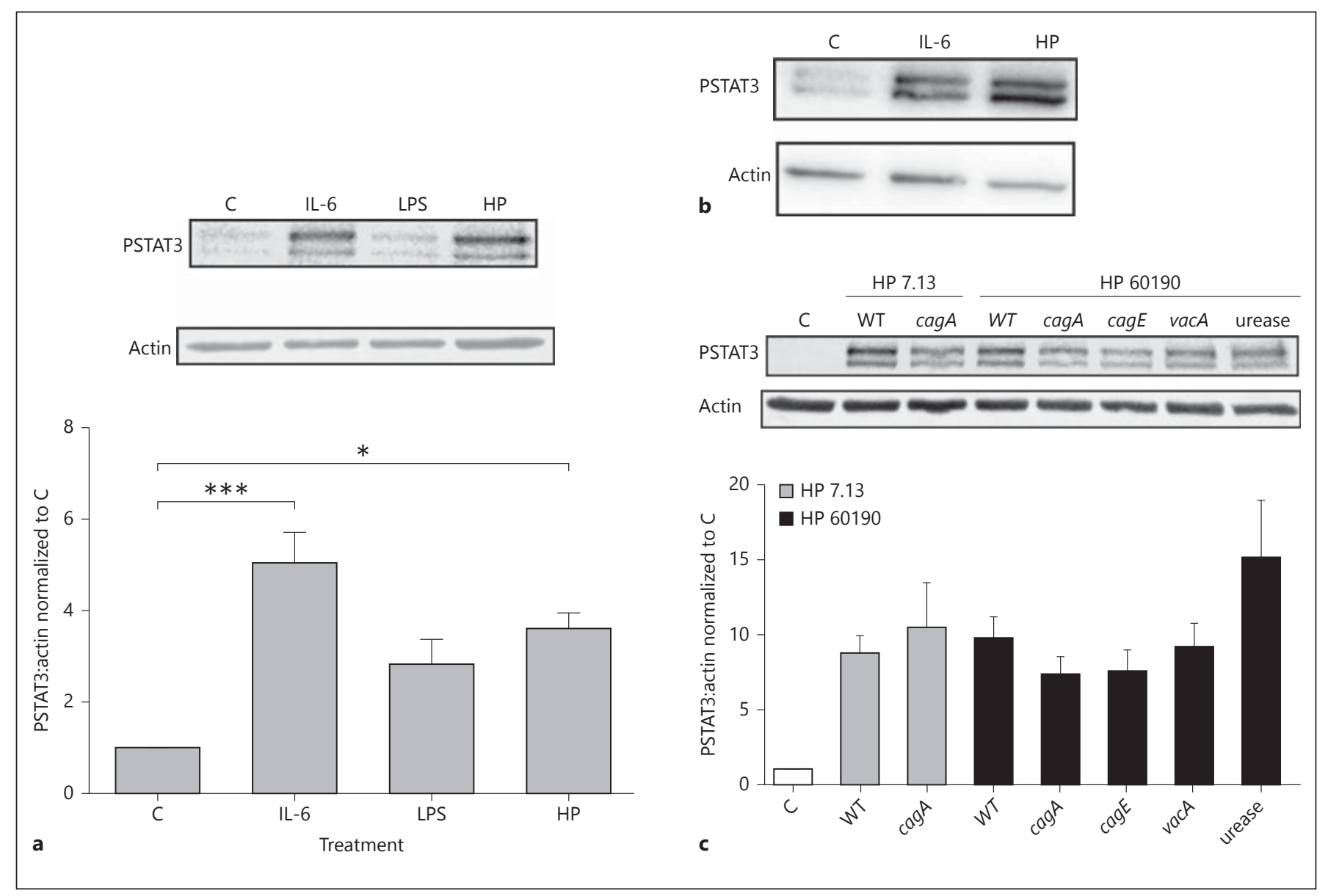

Fig. 1. H. pylori activates the STAT3 pathway in DCs. a Lysates from BMDCs incubated with $H$. pylori strain 7.13 at a MOI of 10 : 1, IL-6 (100 ng/ml) or E. coli LPS ( $1 \mathrm{ng} / \mathrm{ml})$ for $20 \mathrm{~h}$ were subjected to immunoblot analysis to examine changes in STAT3 phosphorylation. The graph represents the densitometric analysis of PSTAT3 bands normalized to actin bands, normalized to control-treated cells. ${ }^{*} \mathrm{p}<0.05 ;{ }^{* * *} \mathrm{p}<0.001$ using the Kruskal-Wallis test $(\mathrm{n}=5)$. b Lysates from splenic-derived DCs incubated with $H$. pylori strain 7.13 at a MOI of $10: 1$ or IL-6 $(100 \mathrm{ng} / \mathrm{ml})$ for $20 \mathrm{~h}$ were subjected

\section{Results}

\section{H. pylori Infection Activates STAT3 in DCs}

To determine whether $H$. pylori infection induces activation of the STAT3 pathway in DCs, expression of PSTAT3 was measured in BMDC lysates following infection with the carcinogenic $H$. pylori strain 7.13 at a MOI of 10:1. Similar to cells treated with the known STAT3 activator IL-6, DCs incubated with $H$. pylori showed increased phosphorylation of STAT3 in comparison with uninfected control and LPS-treated DCs (fig. 1a). Consistent with the findings in BMDCs, an increase in STAT3

to immunoblot analysis to determine changes in STAT3 phosphorylation. c Lysates from BMDCs incubated with $H$. pylori strain 7.13, its isogenic cagA-mutant or H. pylori strain 60190 and its isogenic cagA-, $c a g E-$, vacA- and urease-mutants, at a MOI of 10:1 for $20 \mathrm{~h}$ were subjected to immunoblot analysis to determine changes in STAT3 phosphorylation. The graph represents the densitometric analysis of PSTAT3 bands normalized to actin bands, normalized to control-treated cells. a-c $\mathrm{C}=\mathrm{Control}$; $\mathrm{HP}=H . p y$ lori strain. a, c Columns: means, bars: SEM.

phosphorylation was detected in isolated murine splenicderived DCs indicating that this finding was not unique to BMDCs (fig. 1b). Next, we determined if specific bacterial virulence factors were responsible for the phosphorylation of STAT3. Expression of PSTAT3 was measured in BMDC lysates following infection with either $H$. pylori strain 7.13 or strain 60190 , and corresponding isogenic cagA-, cagE-, vacA- and urease-mutant strains. $H$. pylori strain $7.13 \mathrm{cag} A$ - as well as strain 60190 isogenic cagA-, cagE-, vacA- and urease-mutants increased PSTAT3 expression in DC lysates that was comparable to the corresponding parental WT strains (fig. 1c). 


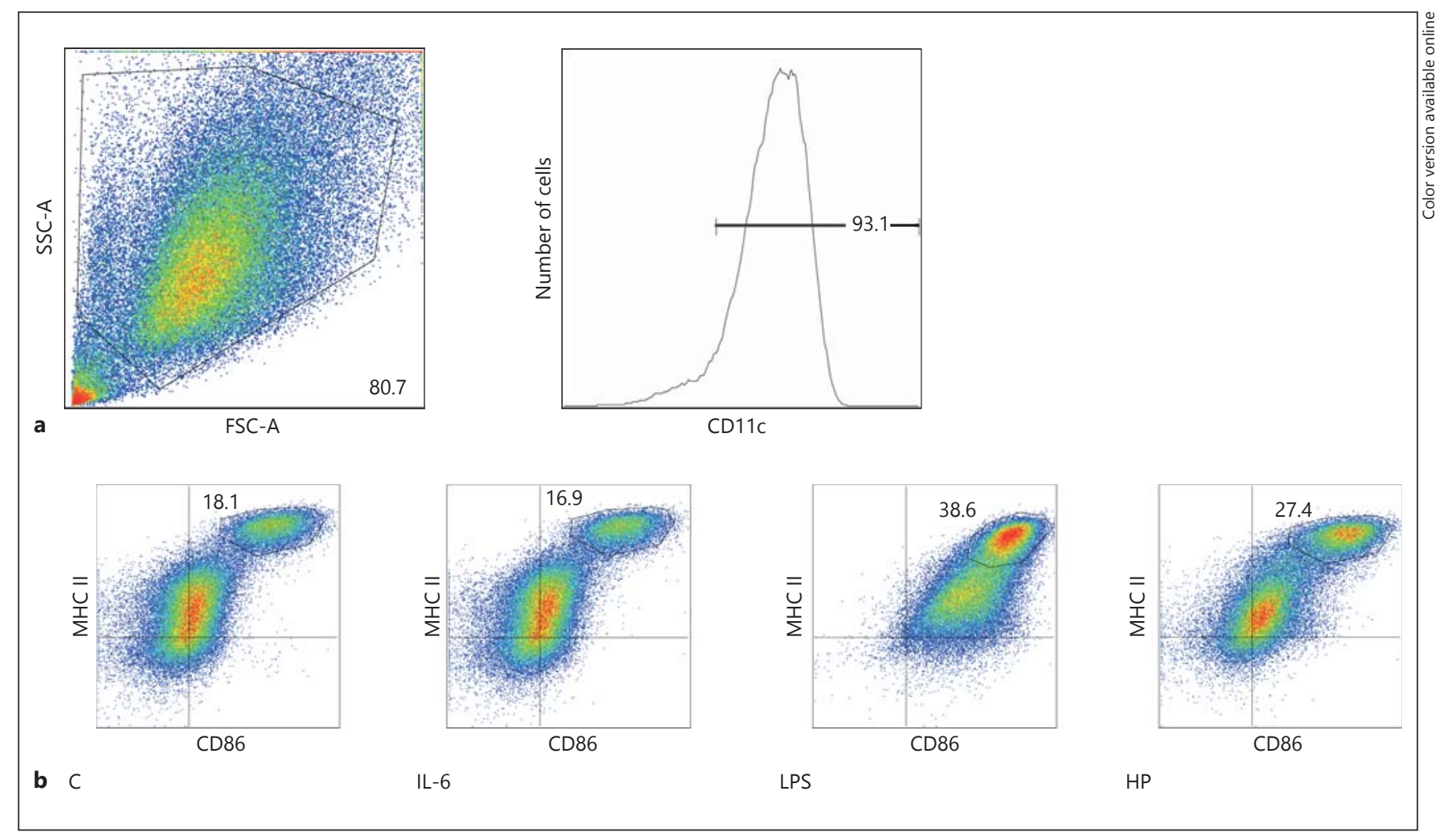

Fig. 2. H. pylori infection induces expression of DC maturation markers. a Live BMDCs were selected based on their size (forward-scatter characteristic, FSC), complexity (side-scatter characteristic, SSC) and expression of the DC-specific marker CD11c. b BMDCs were incubated with $H$. pylori strain 7.13 at a MOI of 10:1, IL-6 (100 ng/ml) or E. coli LPS (1 ng/ml) for $20 \mathrm{~h}$. Flow cytometry analysis was used to quantify the population expressing high levels of the maturation markers CD86 and MHC class II. Cells in the gated population in the upper right quadrant of each graph represent the DCs with a high expression of both markers (i.e. mature DCs). Quadrants were set using FMO staining controls. Data are from 1 representative experiment. c Quantification of gated CD86 ${ }^{\text {hi }}$ MHC II ${ }^{\text {hi }}$ DCs. ${ }^{*}$ p $<0.05$ using a Kruskal-Wallis test $(n=6)$.

\section{H. pylori Infection Upregulates Expression of DC Maturation Markers}

We next assessed the effect of $H$. pylori infection on DC maturation. BMDCs were treated with IL-6 (100 ng/ $\mathrm{ml})$, E. coli LPS ( $1 \mathrm{ng} / \mathrm{ml})$ or $H$. pylori strain 7.13 at a MOI of 10:1 and incubated for $20 \mathrm{~h}$. Untreated cells served as controls. DCs from each treatment condition were stained with $\alpha \mathrm{CD} 11 \mathrm{c}, \alpha \mathrm{CD} 86$ and $\alpha \mathrm{MHC}$ class II fluorophores,

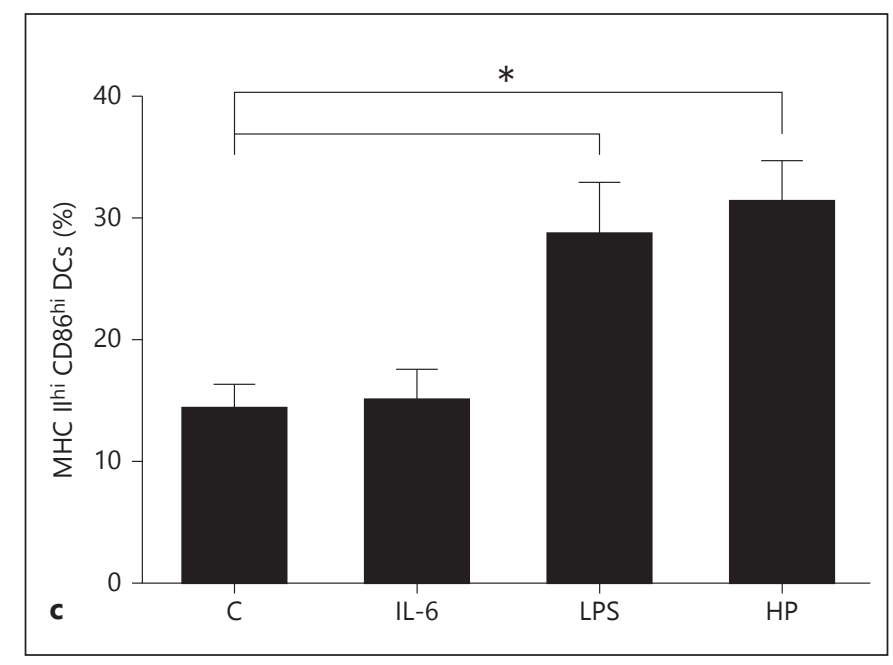

H. pylori Activates STAT3 in Dendritic 


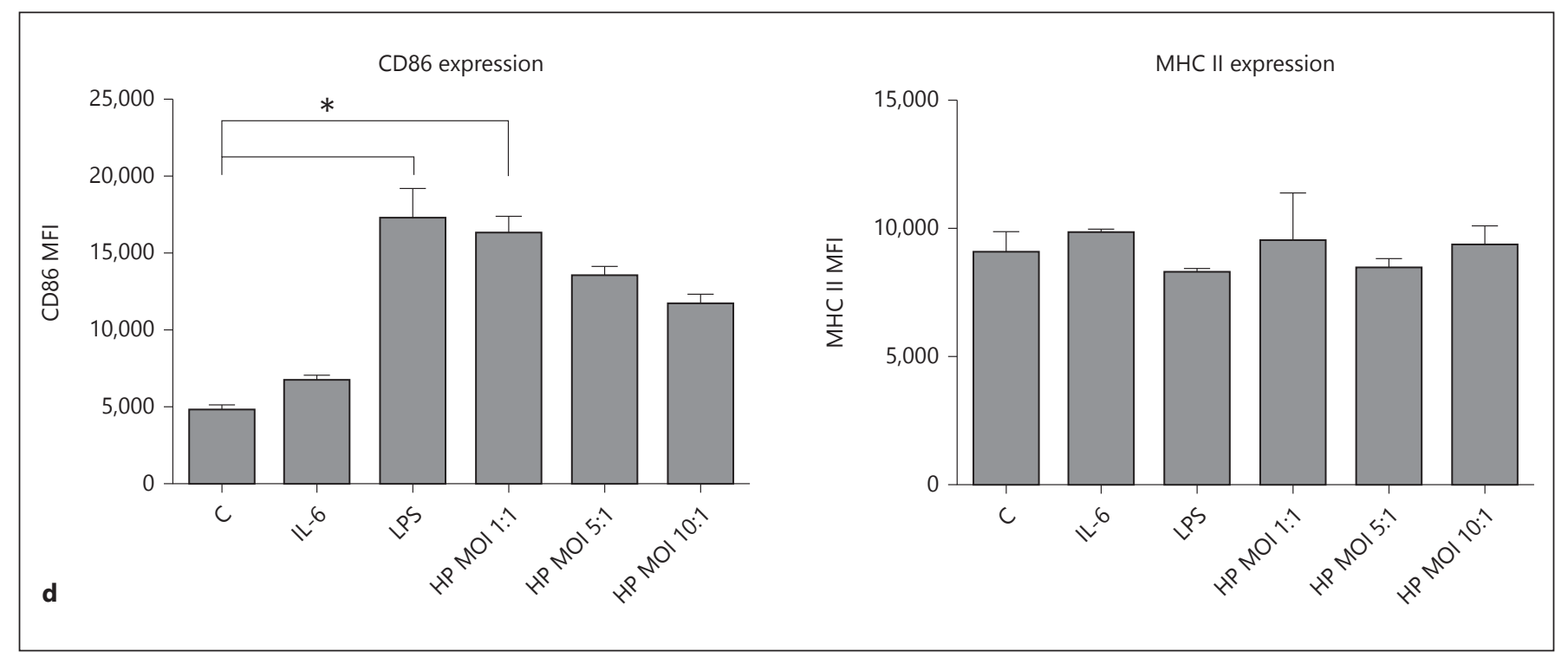

Fig. 2. H. pylori infection induces expression of DC maturation markers. d Splenic DCs were incubated with $H$. pylori strain 7.13 (MOI 10:1, 5:1 or 1:1), IL-6 (100 ng/ml) or E. coli LPS $(1 \mu \mathrm{g} / \mathrm{ml})$ for $20 \mathrm{~h}$. Flow cytometry analysis was used to quantify the population expressing high levels of the maturation markers CD86 and MHC class II in live splenic DCs. Live splenic DCs were selected based on exclusion of the 7-AAD viability staining solution, size

proportion of $\mathrm{MHC} \mathrm{II}^{\text {hi }} \mathrm{CD} 86^{\text {hi }} \mathrm{CD} 11 \mathrm{c}^{+}$DCs to an extent similar to DCs treated with low-concentration E. coli LPS. In cells treated with IL-6, the expression of these maturation markers was comparable to untreated (control) cells (fig. 2b, c).

Next, we assessed the expression of maturation markers in isolated splenic DCs. Isolated splenic DCs displayed a high level of spontaneous maturation. Similar to BMDCs, H. pylori infection (MOI 1:1) increased the proportion of $\mathrm{MHC} \mathrm{II}^{\mathrm{hi}} \mathrm{CD} 86^{\mathrm{hi}} \mathrm{CD} 11 \mathrm{c}^{+}$DCs (online suppl. fig. S1; for all online suppl. material, see www.karger.com/ doi/10.1159/000368232). However, when the multiplicity of infection increased to 5:1 and 10:1, the degree of maturation was comparable to the untreated controls. We next measured expression of the maturation marker CD86, as assessed by the mean fluorescence intensity (MFI) of CD86 (fig. 2d). H. pylori infection at the low MOI of 1:1 increased the MFI of CD86. Interestingly, increasing the MOI of $H$. pylori ameliorated the increased CD86 expression in splenic DCs in a dose-dependent manner (fig. 2d). Taken together, these findings suggest that $H$. pylori is able to inhibit DC maturation at an increased MOI. H. pylori infection did not alter the MFI of MHC II in isolated splenic DCs in comparison with controls. and complexity (FSC and SSC, respectively), and expression of the DC-specific marker CD11c (gating strategy shown in online suppl. fig. S1). The MFI of CD86 and MHC II expression was quantified in this population of cells. ${ }^{*} \mathrm{p}<0.05$ using the Kruskal-Wallis test $(\mathrm{n}=3)$. b-d C $=$ Control; HP $=H$. pylori strain. c, d Columns: means, bars: SEM.

\section{STAT3 Inhibits DC Maturation During H. pylori Infection}

Previous studies suggest that STAT3 activation is a negative regulator of DC function and maturation [12]. To characterize the effect of $H$. pylori-induced STAT3 activation on DC maturation, we utilized BMDCs obtained from mice in which the STAT3 gene was targeted for deletion in DCs using a CD11c-Cre transgene as described previously [12]. DC-specific $\mathrm{Cre}^{+}$STAT3 $\mathrm{KO}$ and littermate $\mathrm{Cre}^{-}$(WT) DCs were treated with IL-6 $(100 \mathrm{ng} / \mathrm{ml})$, E. coli LPS $(1 \mathrm{ng} / \mathrm{ml})$ or H. pylori strains 7.13 or 60190 . Sets of STAT3 KO and WT DCs were then lysed and immunoblotted to determine STAT3 expression and activation. In comparison with DCs from control littermates, STAT3 $\mathrm{KO}\left(\mathrm{Cre}^{+}\right)$DCs lacked STAT3 phosphorylation in response to either $H$. pylori infection or IL-6 treatment, confirming the absence of STAT3 (fig. 3a). In parallel, flow cytometry was performed to assess the expression of the DC maturation markers CD86 and MHC class II. H. pylori-infected STAT3 KO DCs displayed enhanced maturation as assessed by expression of maturation markers using flow cytometry (fig. 3b, c). Taken together, these studies suggest that STAT3 activation in DCs blunts maturation. 


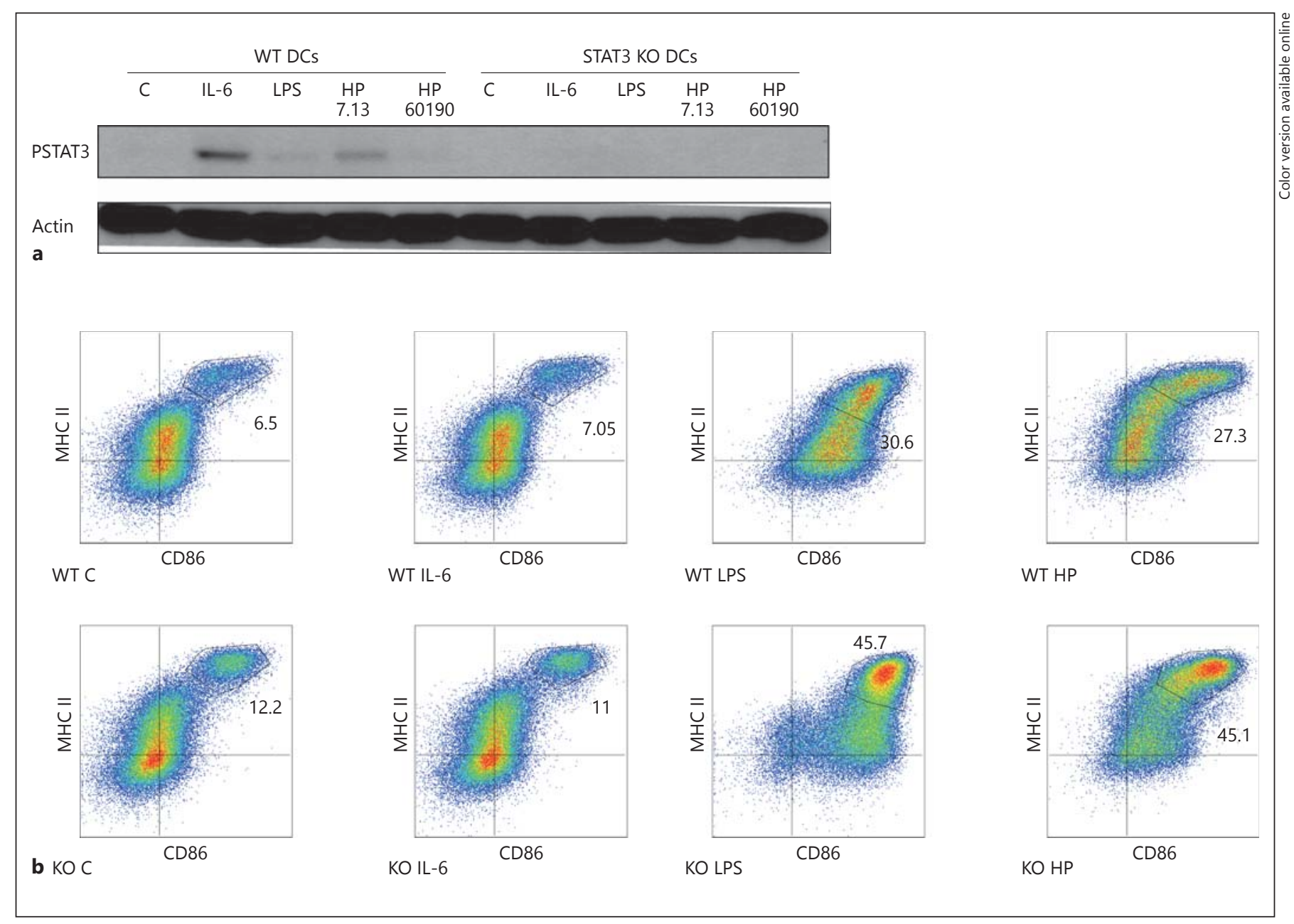

Fig. 3. STAT3 KO DCs express enhanced levels of maturation markers in response to $H$. pylori infection. a Lysates from STAT3 $\mathrm{KO}\left(\mathrm{Cre}^{+}\right)$and WT (littermate $\mathrm{Cre}^{-}$control) BMDCs incubated with $H$. pylori strains 7.13 and 60190 at a MOI of 25:1, IL-6 (100 $\mathrm{ng} / \mathrm{ml})$ or E. coli LPS (1 ng/ml) for $20 \mathrm{~h}$ in DC media were subjected to immunoblotting analysis to determine changes in STAT3 phosphorylation. b STAT3 KO and WT BMDCs were incubated with $H$. pylori strain 7.13 at a MOI of 25:1, IL-6 $(100 \mathrm{ng} / \mathrm{ml})$ or E. coli LPS ( $1 \mathrm{ng} / \mathrm{ml})$ for $20 \mathrm{~h}$ in DC media. Flow cytometry analysis was used to quantify the population expressing high levels of the maturation markers CD86 and MHC class II. Cells in the gated population in the upper right quadrant of each graph represent the BMDCs with a high expression of both markers (i.e. mature DCs). c Quantification of gated CD86 ${ }^{\text {hi }} \mathrm{MHC}$ II ${ }^{\text {hi }}$ DCs. Columns: means, bars: SEM. ${ }^{*} \mathrm{p}<0.05{ }^{* *} \mathrm{p}<0.01$ using the Kruskal-Wallis test $(\mathrm{n}=$ 4). a-c $\mathrm{C}=$ Control; $\mathrm{HP}=H$. pylori strain.

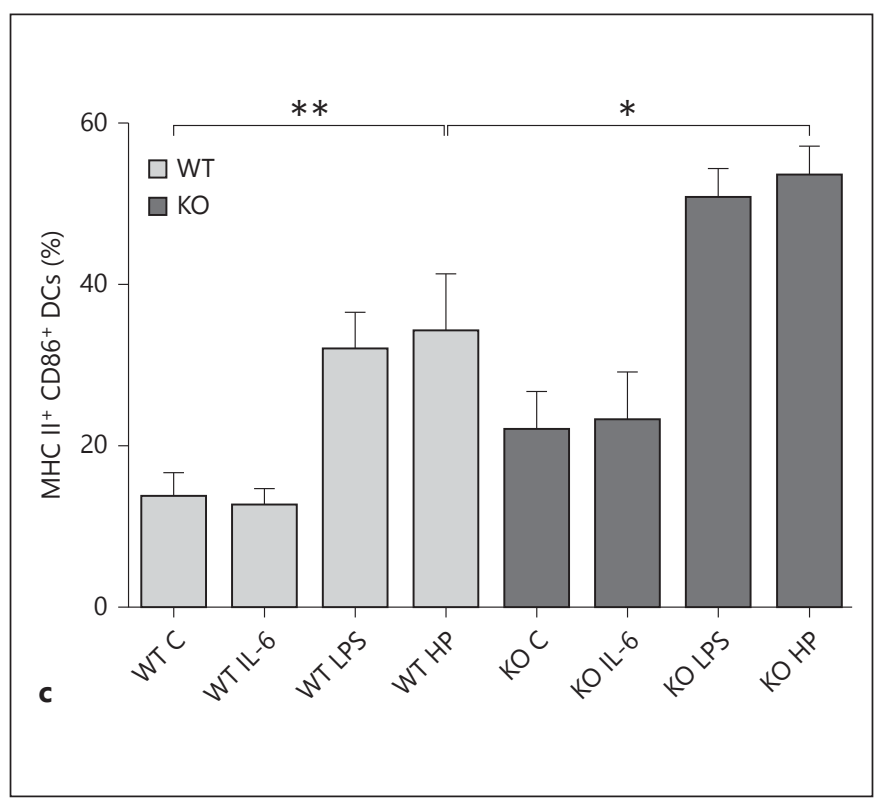


Activated DCs Secrete Immunosuppressive IL-10 in

Response to $\mathrm{H}$. pylori Infection

As the cytokines released from DCs instruct the T cell phenotype that develops, and thus dictate the adaptive immune response, we examined the cytokine release profile from $H$. pylori-infected DCs. H. pylori treatment significantly increased the levels of the anti-inflammatory cytokine IL-10 in the BMDC culture supernatants compared to control, IL-6-, and LPS-treated cell supernatants (fig. 4a). The levels of the proinflammatory cytokine IL$1 \beta$ were also increased in $H$. pylori-infected BMDCs compared to controls and LPS-treated cells (fig. 4a). Furthermore, both $H$. pylori and $E$. coli LPS induced comparable levels of increased secretion of IL-6, IL-25, IL-13, IL-17A, TNFa and IL-23 in the DC culture supernatants in comparison with the controls or IL-6-treated DC supernatants (fig. 4b). Similar to BMDCs, $H$. pylori infection significantly increased levels of IL-10 and IL- $1 \beta$ in isolated splenic DC culture supernatants compared to in the controls (fig. 4c).

\section{H. pylori-Mediated IL-10 Secretion Induces STAT3}

Activation in DCs and Inhibits Maturation

Cytokines including IL- 6 or IL-10 activate the STAT3 pathway. As a marked increase in IL-10 secretion was identified in $H$. pylori-infected DC supernatants in comparison with the controls or the LPS-treated cells, we next determined whether the increased IL-10 secretion was responsible for STAT3 phosphorylation. To investigate the functional effects of DC IL-10 secretion, DCs were incubated with a neutralizing $\alpha$-IL-10 antibody $(1 \mu \mathrm{g} / \mathrm{ml})$ in the presence or absence of $H$. pylori. DCs were lysed and immunoblotting was performed to examine the phosphorylation of STAT3. Treatment with the $\alpha$-IL-10 antibody abrogated the STAT3 phosphorylation induced by H. pylori in the DCs (fig. 5a). Similarly, a-IL-10 treatment prevented STAT3 phosphorylation in isolated splenic DCs treated with $H$. pylori (fig. 5b). Incubation with an isotype IgG antibody $(1 \mu \mathrm{g} / \mathrm{ml})$ had no effect on $H$. pylorimediated STAT3 phosphorylation.

Previous studies implicate IL-10-mediated STAT3 activation in the inhibition of DC maturation [19]. Therefore we assessed the effect of IL-10 neutralization on the expression of DC maturation markers during $H$. pylori infection. Anti-IL-10 treatment enhanced expression of the maturation markers MHC class II and CD86 in DCs in response to $H$. pylori infection (fig. 5c). In contrast, treatment with an isotype control antibody had no effect on H. pylori-mediated STAT3 phosphorylation or the expression of maturation markers (data not shown).
H. pylori-Mediated IL-10 Secretion by DCs Reduces Secretion of Pro-Inflammatory IL-1 $\beta$

We next determined if the cytokine profile differed in a-IL-10-treated $H$. pylori-infected cells. Administration of the $\alpha$-IL-10 antibody effectively neutralized the IL-10 in the H. pylori-infected DC culture supernatants (fig. 6a). Anti-IL-10 treatment of DCs during infection also resulted in increased secretion of the cytokine IL- $1 \beta$, in comparison with controls or the isotype antibody-treated cells (fig. 6b). IL-1 $\beta$ is a pleiotropic proinflammatory cytokine that is involved in the activation of the immune response and the induction of DC maturation [20]. Taken together, these findings indicate that the IL-10 secreted by $H$. pylori-infected DCs blunts not only DC maturation but also the secretion of the proinflammatory mediator IL$1 \beta$.

\section{Discussion}

The ability to alter and evade the host immune response is crucial for the survival and persistence of H. pylori in the host gastric mucosa. As DCs are key orchestrators of the host immune response, they are ideal targets for the pathogen's immunity-manipulating efforts. Furthermore, altered DC function could promote tumor immune evasion. Current evidence indicates that $H$. pylori infection prevents DC activation and maturation [4-6]. However, the mechanism by which $H$. pylori alters DC function remains unclear.

We showed, for the first time, that $H$. pylori activated the STAT3 pathway in murine BMDCs and isolated splenic DCs. Furthermore, we determined that $H$. pylo$r i$-mediated IL-10 release was responsible for the activation of STAT3. IL-10 is a multifunctional immunoregulatory cytokine that acts as an inhibitor of DC maturation and function, and also drives the production of tolerogenic DCs $[3,21]$. IL-10 also activates the STAT3 pathway [7]. In comparison to DCs treated with E. coli LPS, $H$. pylori-stimulated DCs secreted increased levels of IL-10 and IL-1 $\beta$ in both BMDCs and isolated splenic DCs. These findings are consistent with previous studies that identified increased IL-10 secretion in H. pyloristimulated DCs $[4,5]$. Employing an IL-10-neutralizing antibody, we confirmed that $H$. pylori-mediated IL-10 secretion was sufficient to activate STAT3 in DCs. Thus, although some studies indicate that IL- $1 \beta$ may also activate STAT3 in other cell types, our findings indicate that IL-10 is the key cytokine responsible for STAT3 activation in $H$. pylori-treated DCs. As both IL-6 and IL-10 


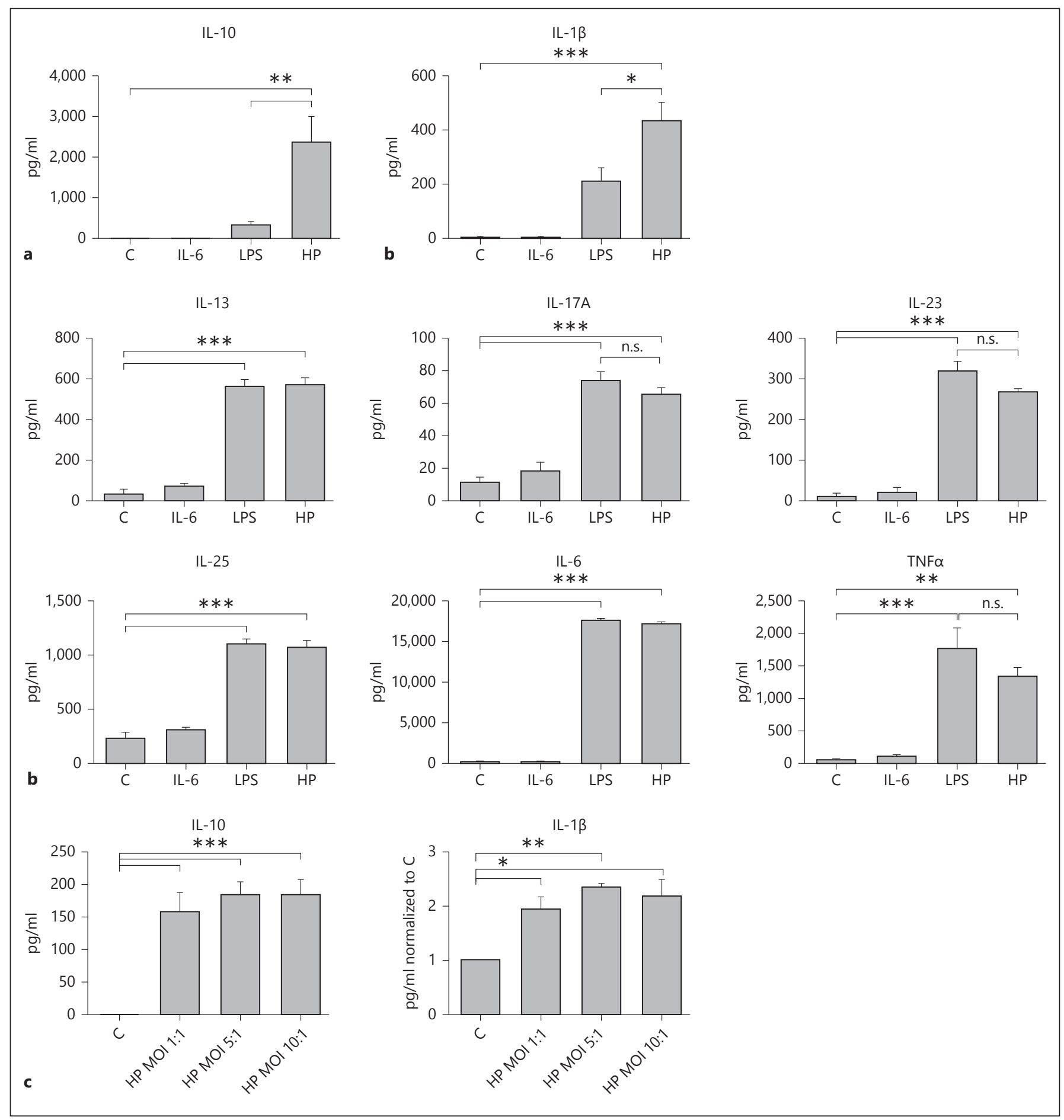

Fig. 4. H. pylori induces secretion of IL-10 from DCs. a The mouse Th17 magnetic bead panel assay was used to assess cytokine secretion in cell supernatants obtained from BMDCs incubated with either E. coli LPS (1 ng/ml), IL-6 (100 ng/ml) or WT H. pylori strain 7.13 (MOI 10:1) for 20 h. ${ }^{*} \mathrm{p}<0.05$; ** $\mathrm{p}<0.01$; ${ }^{* * *} \mathrm{p}<0.001$ using 1-way ANOVA $(\mathrm{n}=4)$. b Increases in IL-6, IL-25, IL-13, IL-17A, TNFa and IL-23 in response to $H$. pylori infection in comparison with treatment with the control and LPS $(\mathrm{n}=4){ }^{*} \mathrm{p}<0.05 ;{ }^{* *} \mathrm{p}<$ $0.01{ }^{* * *} \mathrm{p}<0.001$; n.s. $\mathrm{p}>0.05$. c Mouse quantikine IL- $1 \beta$ and IL10 ELISA kits were used to assess IL- $1 \beta$ and IL- 10 secretion in cell supernatants obtained from control and $H$. pylori strain 7.13-infected (MOI 10:1, 5:1 and 1:1 for $20 \mathrm{~h}$ ) splenic DCs. ${ }^{*} \mathrm{p}<0.05$; ${ }^{* *} \mathrm{p}<0.01$; ${ }^{* * *} \mathrm{p}<0.001$ using a 1-way ANOVA $(\mathrm{n}=3)$. a-c $\mathrm{C}=$ Control; HP $=H$. pylori strain. Columns: means, bars: SEM. 


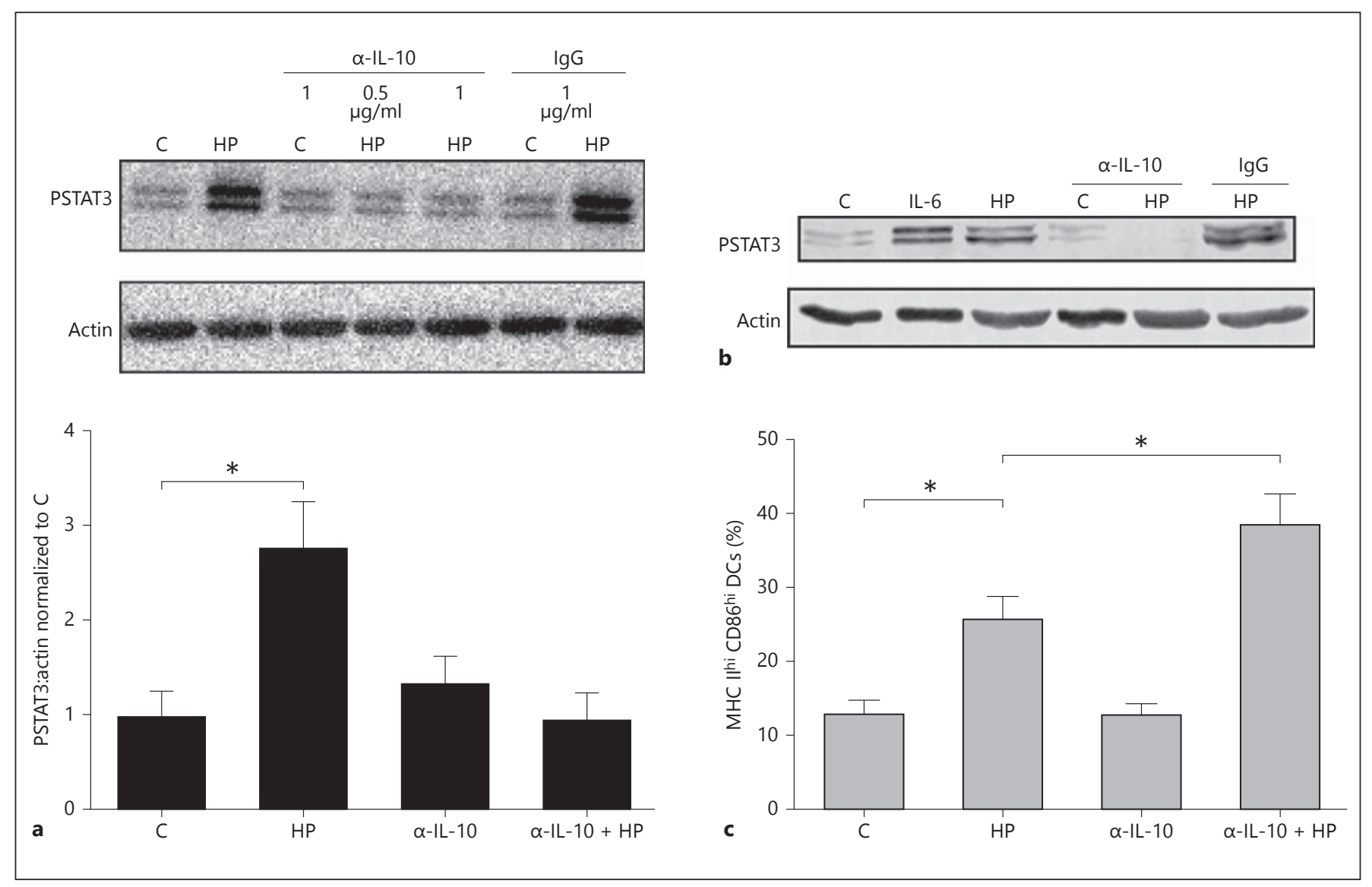

Fig. 5. $\alpha$-IL-10 antibody inhibits $H$. pylori-induced STAT3 phosphorylation in DCs to promote enhanced expression of maturation markers. a Lysates from BMDCs treated with functional grade a-IL-10 antibody ( 0.5 or $1 \mu \mathrm{g} / \mathrm{ml})$ or isotype control IgG antibody $(1 \mu \mathrm{g} / \mathrm{ml})$ in the presence or absence of $H$. pylori, were subjected to immunoblotting analysis to determine STAT3 phosphorylation levels. Densitometric analysis was used to quantify the changes in STAT3 phosphorylation levels. ${ }^{*} \mathrm{p}<0.05$ using the Kruskal-Wallis test $(\mathrm{n}=4)$. $\mathbf{b}$ Lysates from splenic-derived DCs treated with functional grade $\alpha$-IL-10 antibody $(1 \mu \mathrm{g} / \mathrm{ml})$ or isotype control IgG antibody $(1 \mu \mathrm{g} / \mathrm{ml})$ in the presence or absence of $H$. pylori were

activate STAT3 and are secreted by $H$. pylori-infected DCs, this raises the question of why IL-10 has such a potent effect on STAT3 activation. In a previous study, IL-10 promoted sustained STAT3 activation in DCs in comparison with IL-6 [22]; IL-6-mediated transient STAT3 activation induced a proinflammatory response in DCs while IL-10-mediated STAT3 activation promoted an anti-inflammatory response. In our study, anti-IL-10 treatment increased DC expression of MHC II and CD86 in response to $H$. pylori infection, indicating that this IL-10 autocrine/paracrine activation of STAT3 is responsible for the blunted expression of DC subjected to immunoblotting analysis to determine STAT3 phosphorylation levels. Data show a representative blot. c DCs were treated with functional grade $\alpha$-IL-10 antibody $(1 \mu \mathrm{g} / \mathrm{ml})$ or isotype control IgG antibody $(1 \mu \mathrm{g} / \mathrm{ml})$ in the presence or absence of H. pylori at a MOI of 10:1 for $20 \mathrm{~h}$. Flow cytometry analysis was used to quantify the population expressing high levels of the maturation markers CD86 and MHC class II. The graph represents quantification of the gated CD86 ${ }^{\text {hi }}$ MHC II ${ }^{\text {hi }}$ DCs (i.e. mature DCs). ${ }^{*} \mathrm{p}<0.05$ using the Kruskal-Wallis test $(\mathrm{n}=5)$. $\mathbf{a}-\mathrm{c} \mathrm{C}=\mathrm{Con}-$ trol; $\mathrm{HP}=H$. pylori strain. a, c Columns: means, bars: SEM.

maturation markers. Interestingly, neutralization of IL10 also enhanced the secretion of proinflammatory IL$1 \beta$ from $H$. pylori-infected DCs, demonstrating that this IL-10-mediated STAT3 activation plays an immunoregulatory role. IL- $1 \beta$ enhances the proliferation and differentiation of effector T cells including Th17, Th1 and Th2 cells [23]. IL-1 $\beta$ induces the secretion of cytokines such as IL-12 from DCs [24], and breaks peripheral tolerance by inducing resistance to the suppressive functions of FoxP3+ Tregs [25]. Neutralization of IL- $1 \beta$ was found to reduce IL-17A secretion in $\mathrm{CD}^{+} \mathrm{T}$ cells obtained from subjects previously infected with $H$. pylori 


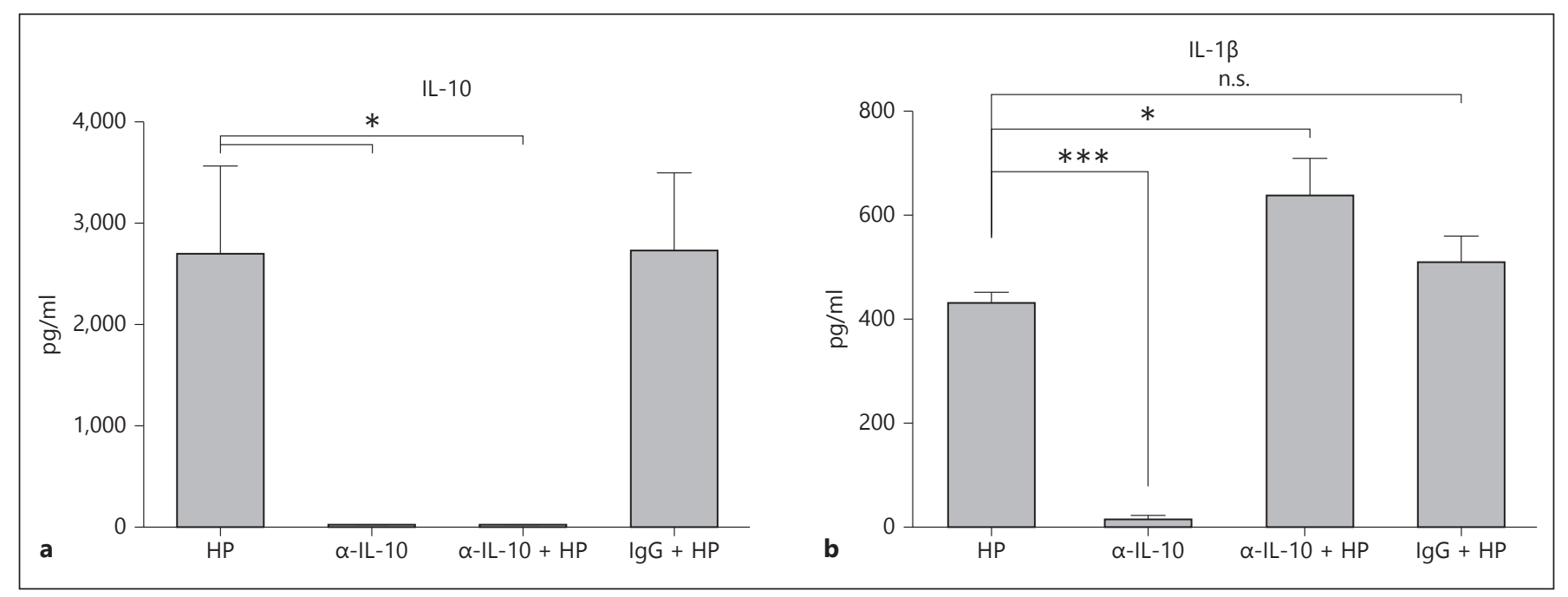

Fig. 6. IL-10 inhibits IL- $1 \beta$ secretion from $H$. pylori-infected DCs. The mouse Th17 magnetic bead panel assay was used to assess IL$10(\mathbf{a})$ and IL-1 $\beta$ (b) cytokine secretion in cell supernatants obtained from DCs incubated with H. pylori for 20 h (MOI 10:1) in the presence or absence of functional grade $\alpha$-IL-10 antibody $(1 \mu \mathrm{g} / \mathrm{ml})$ or a control IgG antibody $(1 \mu \mathrm{g} / \mathrm{ml}) .{ }^{*} \mathrm{p}<0.05$; ${ }^{* *} \mathrm{p}<$ 0.001 ; n.s. $\mathrm{p}>0.05$ using a 1-way ANOVA $(\mathrm{n}=4)$. $\mathbf{a}, \mathbf{b} \mathrm{C}=$ Control; $\mathrm{HP}=H$. pylori strain. Columns: means, bars: SEM. cocultured with autologous $H$. pylori-pulsed antigenpresenting cells [26]. Secretion of this proinflammatory cytokine by DCs may contribute to the chronic gastritis characteristic of $H$. pylori infection.

In order to specifically address the role of STAT3 activation in the prevention of DC maturation during $H$. $p y$ lori infection, we employed a genetic deletion model of STAT3. H. pylori infection induced greater expression of the maturation markers MHC II and CD86 in STAT3-KO DCs when compared to control DCs. Kaebisch et al. [27] used STATTIC, a chemical inhibitor of STAT3, to attempt to block STAT3 activation and characterize the effect on H. pylori-treated human DCs. STATTIC treatment alone was not able to block STAT3 activation and did not alter DC maturation. However, when STATTIC was used in combination with anti-IL-10 treatment, both the inhibition of STAT3 activation and a corresponding increase in DC maturation were identified. Their study supports our results, specifically addressing the role of STAT3 in DC maturation. The role of STAT3 during H. pylori infection characterized in our study is consistent with the current literature that indicates that STAT3 is a negative regulator of DC maturation and function [7, 12,28].

The exact bacterial factors which promote IL-10 secretion and STAT3 activation in DCs have still to be elucidated. We found that isogenic mutant strains lacking either CagA, CagE, VacA or urease were still capable of activating STAT3, indicating that these bacterial factors were not required for STAT3 activation. Furthermore, we found that antibiotic-treated $H$. pylori still induced STAT3 activation (data not shown), indicating that viable bacteria were not required. In support of our findings, previous studies indicate that the DC sensing of bacterial products by Toll-like receptor 2 regulates IL-10 secretion [29]. Furthermore, Shiu et al. [30] showed that Toll-like receptor 2 increased IRAK-M signaling, thereby contributing to IL-10 secretion during $H$. pylori infection. Alternatively, both $\gamma$-glutamyl transpeptidase and $\mathrm{s} 2 / \mathrm{m} 2$ vacuolating cytotoxin secreted from $H$. pylori have been shown to contribute to the development of tolerizing DCs [31]. More recently, Kaebisch et al. [27] showed a reduction but not complete inhibition of IL-10 and PSTAT3 in human DCs infected with an isogenic cagAmutant of strain G27 in comparison with the WT strain. However, another study found comparable levels of IL10 secretion following the infection of human DCs with cag pathogenicity island-positive and negative strains [32]. Similarly, we did not detect a significant reduction in PSTAT3 in DCs infected with isogenic cagA- or cagEmutants. Methodologic differences may account for the apparently conflicting results. Additional studies will be required to delineate the exact bacterial factors required to activate STAT3.

Dysregulation of STAT3 is found in many human cancers including gastric cancers, and it correlates with both tumor progression and poor prognosis [7]. STAT3 
Fig. 7. Proposed model of DC responses to H. pylori infection. H. pylori infection induces immature DCs (iDCs) to secrete IL10 , which acts in an autocrine and paracrine fashion to activate STAT3 in DCs, thereby blunting DC maturation, reducing expression of MHC II and CD86 and secretion of IL- $1 \beta$ from DCs.

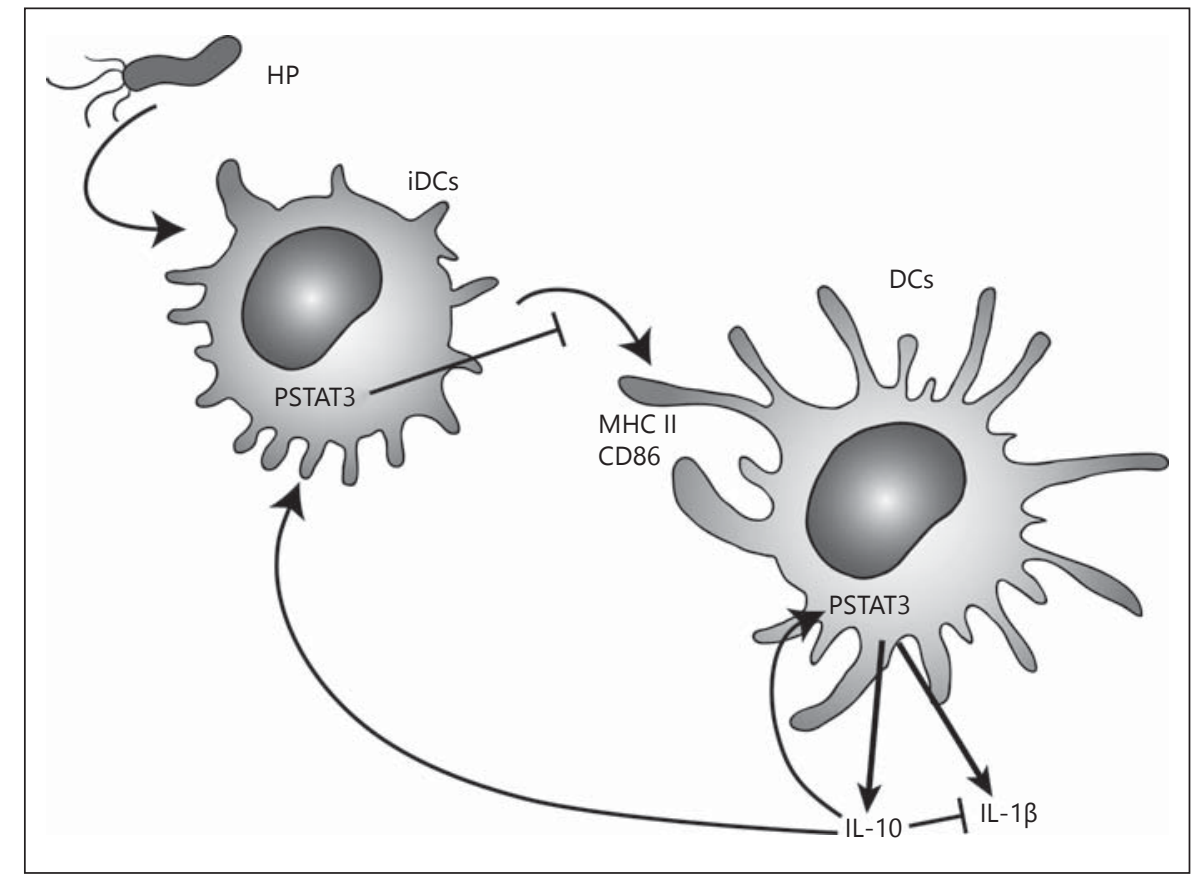

activation is detected in $H$. pylori-infected gastric tissue in humans, and in the gerbil model STAT3 activation is associated with carcinogenesis [15]. Current evidence indicates that STAT3 activation in DCs supports a protumorigenic environment. Many tumors secrete high levels of vascular endothelial growth factor, which can activate STAT3 in DCs, preventing their maturation and thus decreasing host immune tumor surveillance [7]. Furthermore, STAT3-depleted DCs are more resistant to cancer cell-derived inhibitory factors [28]. These STAT3-deficient DCs are more potent activators of T cells and have a high capacity to induce Th1 responses [28]. Indeed, several studies have determined that $H$. pylori-stimulated DCs promote the development of Tregs in vitro $[4-6,27]$ and an increase in infiltrating Tregs has been detected in murine models of infection $[4,5]$ as well as in the gastric mucosa of infected humans [33]. Of interest, an increase in Tregs is detected in the gastric mucosa of $H$. pylori-infected subjects with gastric adenocarcinoma in comparison with $H$. pylori-mediated chronic gastritis or dysplasia [34]. Thus STAT3 activation in DCs during chronic infection with $H$. $p y$ lori may have significant implications for gastric cancer development.

In conclusion, these results demonstrate that $H$. pylori infection induces the activation of the STAT3 signaling pathway in DCs. As depicted in our proposed model in figure 7, the IL-10 produced by $H$. pylori-stimulated DCs may provide a mechanism for altering the balance between the levels of proinflammatory and immunoregulatory cytokines. Thus $H$. pylori-stimulated DCs may prevent a proper adaptive immune response, thereby favoring $H$. pylori persistence and reducing gastric inflammatory damage. Importantly, the IL- 10 secreted by the DCs acted as an autocrine/paracrine activator of STAT3 to blunt DC maturation and induce the production of a tolerogenic DC phenotype. These tolerogenic DCs may inhibit the development of effector T cells, and create a permissive, immunoregulatory environment facilitating bacterial persistence. However, this tolerogenic environment may also decrease DC tumor immunosurveillance to prevent recognition and DC-mediated immune elimination of developing tumor cells, contributing to the development of gastric cancer as seen in $H$. pylori infection. Overall, this study describes a novel mechanism by which $H$. pylori alters the host immune response to facilitate its persistence, a mechanism that may also contribute to the carcinogenic potential of this pathogen.

\section{Acknowledgements}

This work was supported by a research operating grant to N.L.J. (MOP 86619) from the Canadian Institute of Health Research. 


\section{References}

1 Cover TL, Blaser MJ: Helicobacter pylori in health and disease. Gastroenterology 2009; 136:1863-1873.

2 Kusters JG, van Vliet AH, Kuipers EJ: Pathogenesis of Helicobacter pylori infection. Clin Microbiol Rev 2006;19:449-490.

-3 Hubo M, Trinschek B, Kryczanowsky F, Tuettenberg A, Steinbrink K, Jonuleit H: Costimulatory molecules on immunogenic versus tolerogenic human dendritic cells. Front Immunol 2013;4:82.

4 Kao JY, Zhang M, Miller MJ, Mills JC, Wang B, Liu M, Eaton KA, Zou W, Berndt BE, Cole TS, Takeuchi T, Owyang SY, Luther J: Helicobacter pylori immune escape is mediated by dendritic cell-induced Treg skewing and Th17 suppression in mice. Gastroenterology 2010;138:1046-1054.

5 Oertli M, Sundquist M, Hitzler I, Engler DB, Arnold IC, Reuter S, Maxeiner J, Hansson M, Taube C, Quiding-Jarbrink M, Muller A: DCderived IL-18 drives Treg differentiation, murine Helicobacter pylori-specific immune tolerance, and asthma protection. J Clin Invest 2012;122:1082-1096

6 Luther J, Owyang SY, Takeuchi T, Cole TS, Zhang M, Liu M, Erb-Downward J, Rubenstein JH, Chen CC, Pierzchala AV, Paul JA, Kao JY: Helicobacter pylori DNA decreases pro-inflammatory cytokine production by dendritic cells and attenuates dextran sodium sulphate-induced colitis. Gut 2011;60:1479_ 1486.

7 Lin A, Schildknecht A, Nguyen LT, Ohashi PS: Dendritic cells integrate signals from the tumor microenvironment to modulate immunity and tumor growth. Immunol Lett 2010;127:77-84.

$>$ Kim DJ, Chan KS, Sano S, Digiovanni J: Signal transducer and activator of transcription 3 (STAT3) in epithelial carcinogenesis. Mol Carcinog 2007;46:725-731.

$>9$ Reich NC, Liu L: Tracking STAT nuclear traffic. Nat Rev Immunol 2006;6:602-612.

$>10$ Kisseleva T, Bhattacharya S, Braunstein J, Schindler CW: Signaling through the JAK/ STAT pathway, recent advances and future challenges. Gene 2002;285:1-24.

$>11$ Levy DE, Darnell JE Jr: Stats: transcriptional control and biological impact. Nat Rev Mol Cell Biol 2002;3:651-662.

-12 Melillo JA, Song L, Bhagat G, Blazquez AB, Plumlee CR, Lee C, Berin C, Reizis B, Schindler C: Dendritic cell (DC)-specific targeting reveals STAT3 as a negative regulator of DC function. J Immunol 2010;184:26382645.

13 Lutz MB, Rossner S: Factors influencing the generation of murine dendritic cells from bone marrow: the special role of fetal calf serum. Immunobiology 2007;212:855-862.
14 Zheng PY, Jones NL: Helicobacter pylori strains expressing the vacuolating cytotoxin interrupt phagosome maturation in macrophages by recruiting and retaining TACO (coronin 1) protein. Cell Microbiol 2003;5: 25-40.

15 Bronte-Tinkew DM, Terebiznik M, Franco A, Ang M, Ahn D, Mimuro H, Sasakawa C, Ropeleski MJ, Peek RM Jr, Jones NL: Helicobacter pylori cytotoxin-associated gene A activates the signal transducer and activator of transcription 3 pathway in vitro and in vivo. Cancer Res 2009;69:632-639.

16 Niemand C, Nimmesgern A, Haan S, Fischer P, Schaper F, Rossaint R, Heinrich PC, Muller-Newen G: Activation of STAT3 by IL-6 and IL-10 in primary human macrophages is differentially modulated by suppressor of cytokine signaling 3. J Immunol 2003; 170:3263-3272.

17 Foti M, Granucci F, Aggujaro D, Liboi E, Luini W, Minardi S, Mantovani A, Sozzani S, Ricciardi-Castagnoli P: Upon dendritic cell (DC) activation, chemokines and chemokine receptor expression are rapidly regulated for recruitment and maintenance of DC at the inflammatory site. Int Immunol 1999;11:979986.

18 Oliver AM, Grimaldi JC, Howard MC, Kearney JF: Independently ligating CD38 and Fc gammaRIIB relays a dominant negative signal to B cells. Hybridoma 1999;18:113-119.

19 Liu WH, Liu JJ, Wu J, Zhang LL, Liu F, Yin L, Zhang MM, Yu B: Novel mechanism of inhibition of dendritic cells maturation by mesenchymal stem cells via interleukin-10 and the JAK1/STAT3 signaling pathway. PLoS One 2013;8:e55487.

20 Banchereau J, Steinman RM: Dendritic cells and the control of immunity. Nature 1998; 392:245-252.

-21 Corinti S, Albanesi C, la Sala A, Pastore S, Girolomoni G: Regulatory activity of autocrine IL-10 on dendritic cell functions. J Immunol 2001;166:4312-4318.

22 Braun DA, Fribourg M, Sealfon SC: Cytokine response is determined by duration of receptor and signal transducers and activators of transcription 3 (STAT3) activation. J Biol Chem 2013;288:2986-2993.

23 Ben-Sasson SZ, Hu-Li J, Quiel J, Cauchetaux S, Ratner M, Shapira I, Dinarello CA, Paul WE: IL-1 acts directly on CD4 T cells to enhance their antigen-driven expansion and differentiation. Proc Natl Acad Sci U S A 2009; 106:7119-7124.

24 Wesa AK, Galy A: IL-1 beta induces dendritic cells to produce IL-12. Int Immunol 2001;13: 1053-1061.
25 O'Sullivan BJ, Thomas HE, Pai S, Santamaria P, Iwakura Y, Steptoe RJ, Kay TW, Thomas R: IL-1 beta breaks tolerance through expansion of CD25+ effector T cells. J Immunol 2006; 176:7278-7287.

26 Serelli-Lee V, Ling KL, Ho C, Yeong LH, Lim GK, Ho B, Wong SB: Persistent Helicobacter pylori-specific Th17 responses in patients with past $H$. pylori infection are associated with elevated gastric mucosal IL-1beta. PLoS One 2012;7:e39199.

27 Kaebisch R, Mejias-Luque R, Prinz C, Gerhard M: Helicobacter pylori cytotoxin-associated gene A impairs human dendritic cell maturation and function through IL-10-mediated activation of STAT3. J Immunol 2014; 192:316-323.

28 Iwata-Kajihara T, Sumimoto H, Kawamura N, Ueda R, Takahashi T, Mizuguchi H, Miyagishi M, Takeda K, Kawakami Y: Enhanced cancer immunotherapy using STAT3-depleted dendritic cells with high Th1-inducing ability and resistance to cancer cell-derived inhibitory factors. J Immunol 2011;187:2736.

29 Rad R, Ballhorn W, Voland P, Eisenacher K, Mages J, Rad L, Ferstl R, Lang R, Wagner H, Schmid RM, Bauer S, Prinz C, Kirschning CJ, Krug A: Extracellular and intracellular pattern recognition receptors cooperate in the recognition of Helicobacter pylori. Gastroenterology 2009; 136:2247-2257.

30 Shiu J, Czinn SJ, Kobayashi KS, Sun Y, Blanchard TG: IRAK-M expression limits dendritic cell activation and proinflammatory cytokine production in response to Helicobacter pylori. PLoS One 2013;8:e66914.

-31 Oertli M, Noben M, Engler DB, Semper RP, Reuter S, Maxeiner J, Gerhard M, Taube C, Muller A: Helicobacter pylori gamma-glutamyl transpeptidase and vacuolating cytotoxin promote gastric persistence and immune tolerance. Proc Natl Acad Sci U S A 2013;110:3047-3052.

32 Hoces de la Guardia A, Staedel C, Kaafarany I, Clement A, Roubaud Baudron C, Megraud F, Lehours P: Inflammatory cytokine and microRNA responses of primary human dendritic cells cultured with Helicobacter pylori strains. Frontiers Microbiol 2013;4:236.

33 Cook KW, Letley DP, Ingram RJ, Staples E, Skjoldmose H, Atherton JC, Robinson K: CCL20/CCR6-mediated migration of regulatory $\mathrm{T}$ cells to the Helicobacter pylori-infected human gastric mucosa. Gut 2014;63:15501559.

34 Jang TJ: The number of Foxp3-positive regulatory $\mathrm{T}$ cells is increased in Helicobacter $p y$ lori gastritis and gastric cancer. Pathol Res Pract 2010;206:34-38. 